\title{
Expanding the Teaching Commons: Making the Case for a New Perspective on SoTL
}

\author{
Kim A. Case, PhD \\ Associate Professor of Psychology and Women's Studies \\ University of Houston-Clear Lake
}

As a reflection on O'Meara, Terosky, and Neumann's (2011) work on scholarship of teaching and learning (SoTL) faculty development, this essay describes the benefits

of SoTL to individual faculty and university goals. In support and expansion of arguments advanced by O'Meara et al., this work calls for the use of SoTL faculty development to promote the shared teaching commons, active recruitment of new SoTL scholars, institutionalization of SoTL values, and integration of SoTL initiatives

in both teaching centers and research-focused development offices.

In their insightful chapter, "The Scholarship of Teaching and Learning, Professional Growth, and Faculty Development," O'Meara, Terosky, and Neumann (2011) outline the benefits of administrative and institutional support for advancing faculty involvement in the scholarship of teaching and learning (SoTL). This essay offers a reflection on the invisible benefits that SoTL provides at the individual faculty and institution levels, as well as a new model for advancing faculty development approaches to recruiting and mentoring SoTL scholars. Essentially, the benefit of SoTL lies in its insistence that intellectual discovery extend beyond the isolated classroom investigation and contribute to understanding of learning in the broader pedagogical community. By promoting SoTL benefits, faculty development administrators will aid in moving scholarship on teaching and learning from the background to the forefront in higher education.

\section{Invisible SoTL Benefits for Faculty and Institutions}

As O'Meara et al. (2011) articulated in their chapter, SoTL offers a long list of academic benefits that often remain invisible to both faculty and university administrators. Given that administrators admittedly must attend to broader institutional goals such as publishing research and promoting teaching methods to enhance student learning, SoTL provides a productive approach at the intersection of these goals. The traditional "narrative of constraint" represents a remedial approach to faculty development that emphasizes teaching deficits among faculty and fixing problematic teaching strategies. Rather than perpetuate former models emphasizing the narrative of constraint where faculty needed to be "fixed" (Shulman, 2004), faculty developers and teaching center administrators can support faculty reflection for improvement through promotion of SoTL inquiry. In other words,

By legitimizing the classroom as the source of interesting, consequential questions about teaching and learning, and in recognizing the teacher as the person best suited to formulate and study these questions, the scholarship of teaching and learning reinforces the possibility of the kind of professional growth that comes from within (O'Meara et al., p. 58).

At the same time, faculty engaged in SoTL benefit from the "narrative of growth" that promotes their own reflective inquiry into pedagogical practices and the discovery of approaches that best support student learning. Within the narrative of growth framework for faculty development, SoTL is viewed as supportive guidance to help faculty members work toward their own professional goals of becoming 
exceptional teachers. O'Meara et al. (2011) appropriately pointed out that teaching centers promoting SoTL serve university goals by providing spaces for faculty to pursue intrinsic motivations to improve as professional educators. This "internal impetus" (O'Meara et al., p. 48) drives faculty to continue learning about learning and growing as professionals, which clearly aligns with the institutional goals and growth.

As an example, the teaching center at my university originated from the faculty out of an internal need to share ideas and improve teaching. The faculty development motto of TLEC (Teaching-Learning Enhancement Center) developed into a resounding "by faculty for faculty" to emphasize the focus on the narrative of growth. Through SoTL programs, speakers, workshops, research groups, and conference travel support, TLEC made it possible for faculty to bring their pedagogical discoveries into the shared teaching commons that Huber and Hutchings (2006) described as essential to the SoTL process. The SoTL skills that faculty develop (e.g., collaboration, collegiality, and reflection for informed action and improvement) all transfer to other areas of research and service. Speaking to the core benefit of SoTL, scholarship of teaching and learning provides systematic methods (often new methods from outside disciplines) to investigate learning, ultimately leading to improved teaching approaches shared with the broader community.

\section{Faculty Development to Promote the Shared Teaching Commons}

In recent years, I organized faculty book clubs to read and discuss The Last Lecture (Pausch, 2008), Teaching to Transgress (hooks, 1994), What the Best College Teachers Do (Bain, 2004), and Teaching for Critical Thinking (Brookfield, 2012). Faculty often report back to me that they found the particular book we are reading for that semester lacking in some way. Other faculty tell me they approve of my excellent selection. Regardless of whether these comments rate the book in a positive or negative light, my response is the same. My faculty development goals focus on bringing faculty together in a space for pedagogical reflection and sharing. In other words, the book becomes almost irrelevant as it serves as only a catalyst to bolster our teaching commons. In my role as teaching center director and faculty developer, I attempt to encourage a faculty community of learners spanning a wide variety of disciplines for shared discussion of teaching innovations as well as pedagogical scholarship.

In order to move beyond scholarly or thoughtful teaching to openly shared scholarship of teaching (Shulman, 1993), the instructional reflection, methodology, and final outcomes must be shared with other educators (Huber \& Hutchings, 2006). Promoting recent work to broaden the impact of SoTL in higher education, O'Meara et al. (2011) called for collaboration and conversation around SoTL "to engage a larger group of faculty...beyond the individual classroom" (p. 63). Although individual faculty may not feel compelled to share their SoTL efforts with the broader academic audience via publication, O'Meara et al. rightly argued that faculty developers can contribute to building the teaching commons by encouraging publication. In my view, the role of teaching center directors includes nurturing "partnerships that raise knowledge about learning from anecdotal to systematic" (O'Meara et al., p. 65) and cultivating a culture of the shared teaching commons across the university.

\section{Faculty Development to Recruit New SoTL Scholars}

As a SoTL scholar that became a teaching center administrator, I feel a personal obligation to pass along the benefits of SoTL via my faculty development role. My experience as a Carnegie Academy for the Scholarship of Teaching and Learning (CASTL) Institute scholar introduced me to the importance of sharing pedagogical advancements across disciplinary boundaries and publishing study 
findings in not only SoTL journals, but also more traditional research journals that lack a teaching focus. Through development and implementation of teaching center (TLEC) initiatives, I try to cultivate faculty SoTL interest by encouraging a community of faculty learners, organizing interdisciplinary SoTL research teams, and recruiting new SOTL scholars for the mentoring institute (IISSAM, previously CASTL Institute). In other words, I utilize TLEC as an institutional force to establish and maintain a teaching commons for professional growth and SoTL faculty development. For instance, my role as TLEC Director and CASTL Institute and IISSAM planning committee member allowed me to successfully recruit and mentor faculty as new SoTL scholars, fund their travel to the mentoring institutes, and invite them to present their SoTL studies and findings to the campus faculty, thus expanding the teaching commons and pedagogical learning community. For example, previous CASTL Institute scholars from the University of Houston-Clear Lake returned to campus and presented their SoTL projects on a variety of topics: assessing critical thinking; investigating student bias toward out-groups; exploring a project where students create their own nonprofit organization; and understanding the effectiveness of a policy analysis assignment requiring students to apply theory to real-world problems. When new SoTL scholars presented their study findings at TLEC events, their passion for this scholarship spread among colleagues from disciplines that would otherwise never cross paths. Physics professors gained new ideas from psychology and social work SoTL scholars while education faculty found innovative approaches in the SoTL research of a computer engineering faculty member.

When faculty developers provide spaces for groups of faculty to reflect and explore learning, whether through discussions, book clubs, speakers, or other initiatives, disciplinary boundaries often melt away, making room for innovative interdisciplinary collaborations. At a TLEC-sponsored event, speaker Anthony Herman introduced the faculty to the first day interview activity (Hermann \& Foster, 2008) and inspired faculty from across three schools and four disciplines (psychology, education, computer science, and women's studies) to conduct a study examining the impact of the class interview on student perceptions of the course and their motivations for learning. This first day activity consists of 1 ) the instructor interviewing students to discover their expectations for the course, their educational backgrounds, and their needs as learners, and 2) the students interviewing the instructor about his or her approach to the classroom. The resulting SoTL publication (Case et al., 2008) moved this pedagogical inquiry beyond the individual classroom to not only the shared teaching commons within the university, but also into the broader academic teaching commons while serving two institutional goals, research publication and improved teaching.

Faculty developers, whether in teaching centers, SoTL programs, or research offices, help faculty in their own professional growth when they recruit not only junior, but also midcareer and senior faculty into the field of SoTL. My involvement in the SoTL community directly resulted from the friendly and supportive push from the teaching center director. Faculty interested in studying classroom activities, assignment effectiveness, or the best strategies to enhance learning may not be interested in contributing to the teaching commons without the mentoring of faculty developers to encourage them. As center directors, coordinators of programs and initiatives, and administrators, faculty developers must strengthen the marketing of SoTL as transformative learning on the part of faculty scholars.

As O'Meara et al. (2011) pointed out, some universities recently established entire centers or well-developed campus initiatives (e.g., small grants, poster sessions, SoTL certificates) devoted to SoTL. One approach to help recruit scholars at all career stages, comes from the CASTL Institute (now IISSAM) model. Within this weekend institute, experienced SoTL scholars serve as mentors to new SoTL scholars, providing one-on-one mentoring and detailed feedback to advance their developing SoTL projects. Michael et al. (2010) assessed the CASTL Institute's impact on SoTL scholars and faculty development. Surveys and interviews of 
former Institute participants revealed the Institute had an impact on individual behaviors and attitudes, approaches in the classroom, learning communities within institutions, and the field through increased SoTL conference presentations and publications. On a smaller scale, TLEC (the UHCL teaching center) recruits new SoTL scholars through workshops on SoTL methods, presentations of faculty SoTL projects, national speakers such as Pew Scholar and Carnegie Fellow Randy Bass, travel funds to attend the mentoring institutes, and interdisciplinary SoTL groups that publish articles. Through these efforts, both the institute SoTL mentoring model and the TLEC initiatives serve to transform institutional culture for greater value of scholarship of teaching and learning and the faculty members engaging in this type of research.

\section{Faculty Development to Change Institutional Culture}

In order to further advance SoTL and expand its benefits to the institution, I argue that faculty developers must focus on two main goals: 1) fostering partnerships and collaborations to integrate SoTL into the work of both teaching centers and research development offices; and 2) raising awareness of the value of SoTL among administrators.

Although faculty development encompasses a wide range of administrative positions and goals within centers and offices across institutions, faculty share the common goal of providing pathways for faculty professional growth and improvement. For faculty developers working within teaching centers as well as SoTL programs and centers, the development mission emphasizes improved teaching effectiveness to enhance student learning outcomes. For faculty development offices devoted to research and grant support, faculty productivity in writing and securing grants and publishing research findings is of great importance. O'Meara et al. (2011) suggested that these seemingly divergent goals actually share a common purpose at the intersection known as the scholarship of teaching and learning. Although research-focused faculty development offices are charged with identifying grant opportunities and offering seed funds for faculty research projects such as pilot studies, these efforts often neglect the scholarship of teaching and learning (except when working with education faculty).

O'Meara et al. (2011) described Boyer's (1990) argument that teaching requires intellectual and scholarly substance as a call for appropriate recognition of teaching, rather than viewing teaching as somehow inferior to research scholarship. Unfortunately, those false boundaries between teaching and research still carry with them a hierarchical system that privileges research over teaching. In fact, some faculty feel an academic stigma associated with professional focus on teaching, including scholarship about teaching and learning. Giving an invited workshop to faculty on navigating the journey to becoming a SoTL scholar, a chemistry professor expressed that his interest in SoTL did not align with his field's view of SoTL as "not real research." He felt that his location in a field outside psychology and education meant SoTL would never be valued as contributing to the advancement of chemistry. His concerns are valid and must be met with clear articulation of support from university administrators. Without explicit statements of support for SoTL work, faculty will remain unmotivated to publish in a field that they expect will be devalued by promotion and tenure evaluators.

When I speak with junior faculty at both teaching- and research-focused conferences, they often report receiving the clear message from administrators that SoTL publications would not be viewed positively in promotion and tenure evaluations. These examples illustrate that many faculty possess intrinsic motivations to pursue SoTL work, but are quite concerned this work (even if published) will not be counted toward annual reviews or promotion and tenure. Of course, their very real concerns result in moving away from SoTL for fear of negative repercussions for their careers. To prevent this unfortunate avoidance, administrators at the Dean and Provost levels must be clear that scholarship and 
publication to advance teaching and learning are truly valued and provide recognized benefits toward institutional growth. Formal faculty handbook policies that include statements of support for SoTL as related to reviews and promotion and tenure, as well as departmental, school, and university mission statements or strategic planning documents that include SoTL, will clarify values and support for SoTL faculty development.

\section{My SoTL Journey}

As a graduate student taking a qualitative methodology course, I embarked on a research project to examine the ways White students engage and disengage with course materials addressing race and racism (Case \& Hemmings, 2005). That first study of classroom interactions, resistance, and the impact of both on learning led me into a new world of scholarship I had never considered. During my time as a lecturer teaching race and gender courses, I began a series of pre/post-test studies to determine whether students' attitudes changed as a result of taking these courses (Case, 2007a; Case, 2007b; Case \& Stewart, 2010a; Case \& Stewart, $2010 \mathrm{~b})$. Despite these endeavors and intrinsic interests, I had never even heard of the "scholarship of teaching and learning" or "SoTL" and was only introduced to the field when I joined the faculty at UHCL. In reading "The Scholarship of Teaching and Learning, Professional Growth, and Faculty Development" (O'Meara et al., 2011), I repeatedly thought, "They are telling my story."

My official SoTL story began with my arrival at UHCL when the teaching center director encouraged my application to become a SoTL scholar at the CASTL Institute, where I received exceptional mentoring from Howard University law professor Alice Thomas, as well as from my peer scholars and conference participants. This interdisciplinary exposure provided methodological and pedagogical insights I simply would not have gathered from professionals in my own field. The faculty development support from the university's TLEC director challenged me to dive into SoTL with not only collegial support, but also essential travel funding and peer mentoring to prepare my project. That experience led to my own enthusiastic recruitment of new SoTL scholars and to my position as Director of TLEC two years later. As O'Meara et al. (2011) pointed out, "the scholarship of teaching and learning has been, and continues to be, a transformative concept in higher education" ( p. 45). In support of their argument, the only way that I can accurately describe my professional advancement as an academic is to say that SoTL was transformational in terms of my own career.

My experience and that of the CASTL Institute participants illustrates the need for a new approach to SoTL faculty development. In moving away from the outdated narrative of constraint to a supportive narrative of growth, a new generation of SoTL scholars can be developed to transform the culture that devalues this work. Without access to SoTL mentoring and an institutional culture of SoTL support, I am confident my career would have been much less productive and less rewarding.

\section{Conclusion}

In the next phase of SoTL advancement both nationally and internationally, faculty developers can take the lead in expanding scholarship and elevating the value of SoTL in the academy. Through active recruitment of junior, midcareer, and senior faculty into the interdisciplinary world of SoTL, faculty developers will build the next generation of scholars. Offering faculty skills that translate to more traditional research in their disciplines and to service realms, SoTL expertise provides benefits well beyond the classroom. In addition, SoTL scholars contribute to institutional goals of not only improving teaching for quality student learning experiences, but also publishing research and garner institutional recognition in the academic literature. Partnerships between teaching centers and research development offices to introduce or expand SoTL programs, initiatives, and support 
will maximize the potential of this intersection of interests and goals. When university research and grant offices begin to take SoTL seriously within the mission and vision of support for faculty development, they may see increases in faculty grant-writing, interdisciplinary scholarship, and academic publishing. Breaking down these socially constructed walls between teaching and research will yield long term benefits for the individual faculty, faculty developers, and the institution itself. The myth that frames research and teaching as mutually exclusive is not only outdated, but also harmful to university goals. Future research documenting the impact of newly integrated SoTL initiatives, administrative views, and efforts to formally institutionalize SoTL on faculty engagement in research to enhance teaching and learning will aid faculty developers in more effective SoTL scholar recruitment.

\section{References}

Bain, K. (2004). What the best college teachers do. Cambridge, MA: Harvard University Press.

Boyer, E. (1990). Scholarship reconsidered. San Francisco, CA: Jossey-Bass.

Brookfield, S. (2012). Teaching for critical thinking: Tools and techniques to help students question their assumptions. San Francisco, CA: Jossey-Bass.

Case, K. (2007a). Raising male privilege awareness and reducing sexism: An evaluation of diversity courses. Psychology of Women Quarterly, 31, 426-435.

Case, K. (2007b). Raising white privilege awareness and reducing racial prejudice: Assessing diversity course effectiveness. Teaching of Psychology, 34, 231-235.

Case, K., Bartsch, R., McEnery, L., Hall, S. P., Hermann, A., \& Foster, D. (2008). Establishing a comfortable classroom from day one: Student perceptions of the reciprocal interview. College Teaching, 56, 210214.

Case, K., \& Hemmings, A. (2005). Distancing strategies: White women preservice teachers and anti-racist curriculum. Urban Education, 40, 606-626.
Case, K., \& Stewart, B. (2010a). Changes in diversity course student prejudice and attitudes toward heterosexual privilege and gay marriage. Teaching of Psychology, 37, 172-177.

Case, K., \& Stewart, B. (2010b). Heterosexual privilege awareness, prejudice, and support of gay marriage among diversity course students. College Teaching, 58, 3-7.

Hermann, A. D., \& Foster, D. (2008). Fostering approachability and classroom participation during the first day of class: Evidence for a reciprocal interview activity. Active Learning in Higher Education, 9, 139151.

hooks, b. (1994). Teaching to transgress: Education as the practice of freedom. New York, NY:

Routledge.

Huber, M. T., \& Hutchings, P. (2008). The advancement of learning: Building the teaching commons. San Francisco, CA: Jossey-Bass.

Michael, R., Case, K., Danielson, M., Hill, L., Lochbaum, L., McEnery, L., \& Perkins, K. (2010). Mentoring new scholars of teaching and learning: The national CASTL Institute model. Transformative Dialogues: Teaching and Learning Journal, 3, 1-15. 
O'Meara, K. A., Terosky, A. L., \& Neumann, A. (2011). The scholarship of teaching and learning, professional growth, and faculty development. In P. Hutchings, M. T. Huber, \& A. Ciccone (Eds.), Scholarship of teaching and learning reconsidered: Institutional integration and impact (p. 45-68). San Francisco, CA: Jossey-Bass.
Pausch, R. (2008). The last lecture. New York, NY: Hyperion.

Shulman, L. (1993). Teaching as community property: Putting an end to pedagogical solitude. Change, 25, 6-7.

Shulman, L. (Ed.) (2004). Teaching as community property: Essays on higher education. San Francisco, CA: J ossey-Bass.

Kim A. Case, PhD is an Associate Professor of Psychology and Women's Studies, Director of the Teaching-Learning Enhancement Center, and Women's Studies Program Director at the University of Houston-Clear Lake. She also directs the Psychology Master's program Applied Social Issues subplan. Her research on prejudice confrontation and ally behavior focuses on dominant group responses to prejudice in social contexts. She also studies strategies for raising awareness of heterosexual, gender-conforming, male, and White privilege in educational and community settings. Her book, Deconstructing Privilege: Teaching and Learning as Allies in the Classroom (2013), focuses on pedagogical strategies for privilege studies. 